\title{
Atividade docente no processo de ensino aprendizagem da língua inglesa: caminhos possíveis
}

The teaching practise in the lecturing procedure of the English language learning: possible directions

Camila Vieira Cassiano (USCS) ${ }^{1}$

Ivo Ribeiro de Sá (USCS) ${ }^{2}$

\section{RESUMO}

A partir dos estudos realizados por Guy Brousseau (2008) sobre as Situações Didáticas, o presente trabalho discute as contribuições do conceito de Contrato Didático para o processo ensino-aprendizagem da língua inglesa. O principal objetivo é estabelecer relações entre as interações dos alunos e a atividade docente. Nesse sentido, este estudo apresenta uma revisão bibliográfica que considerou o conceito citado como um meio alternativo de lidar com as dificuldades presentes no cotidiano escolar, além de estabelecer as relações consideradas relevantes para o processo de ensino-aprendizagem de língua estrangeira. Independente das dificuldades do ambiente escolar e particularidades das propostas de ensino, o Contrato Didático se coloca como uma possiblidade de propiciar a melhora da oferta de ensino do idioma para todos os alunos do ensino público.

Palavras-Chave: Aprendizagem, Ensino, Língua Inglesa, Contrato Didático

\begin{abstract}
Trough the studies accomplished by Guy Brousseau (2008) concerning on the Didactic Situations, this paper discusses the contributions of the concept of Didactic Contract to the teaching-learning process of the English language. The main objective is to establish interactions between the students and the teaching practise. In this sense, this study presents a bibliographic review which considered the concept cited as an alternative mean of dealing with the difficulties present in the school daily routine, in addition to establishing the relationships considered relevant for the teaching-learning process of overseas language. Despite of the difficulties of the school environment and particularities of the teaching proposals, the Didactic Contract is considered as a possibility to provide the improvement of the provision of language teaching for all students of public education.
\end{abstract}

Keywords: Learning, teaching, English language, Didactic Contract

\footnotetext{
${ }^{1}$ Universidade Municipal de São Caetano do Sul, São Caetano do Sul, São Paulo, Brasil. Programa de Pós-Graduação em Educação; ORCID: https://orcid.org/0000-0001-8264-1810; camila.vcassiano@gmail.com

${ }^{2}$ Universidade Municipal de São Caetano do Sul, São Caetano do Sul, São Paulo, Brasil. Programa de Pós-Graduação em Educação; ORCID: https://orcid.org/0000-0002-2554-3525; ivo.sa@prof.uscs.edu.br
} 


\section{Introdução}

Segundo as normativas oficiais (BRASIL, 1996; BRASIL, 1998; BRASIL, 2013; BRASIL, 2014; BRASIL, 2017; SÃO PAULO, 2008), o ensino de língua estrangeira é considerado como componente curricular da Educação Básica brasileira e, portanto, deve fazer parte das matrizes curriculares das redes de ensino, tanto pública quanto privada.

Essas normativas tomam como pressupostos que aprender uma nova língua, em qualquer idioma, proporciona aos indivíduos a oportunidade de expandir os horizontes e obter a própria autonomia, capaz de permitir o exercício da cidadania de acordo com os seus respectivos objetivos pessoais, culturais e/ou profissionais.

Entretanto, a oferta de uma língua estrangeira está condicionada à opção que a unidade pública ou privada de ensino faz quando seleciona o idioma que fará parte de seu currículo. O oferecimento se torna obrigatório uma vez que tanto as legislações federais, quanto as estaduais e municipais garantem esse direito e a unidade escolar deverá explicitar essa garantia em seu Projeto Político Pedagógico.

Além disso, a Lei de Diretrizes e Bases nº 9.394/96 (BRASIL, 1996) garante a oferta de ensino a todas as escolas das regiões brasileiras. Nesse sentido, o Governo Federal, por meio do Ministério da Educação, publica os Parâmetros Curriculares Nacionais (BRASIL,1998) como proposta não obrigatória que apresenta para os docentes as orientações para a efetivação da atividade docente no processo de ensino-aprendizagem dos alunos.

Em continuidade a essa política, a Base Nacional Comum Curricular (BRASIL, 2017) e a Proposta Curricular do Estado de São Paulo (SÃO PAULO, 2008) asseveram os conteúdos, no interior de suas habilidades e competências, a serem inseridos no ano letivo de cada ano e/ou ciclo, além das metas e diretrizes também estabelecidas nas ofertas de ensino pelo Plano Nacional de Educação (BRASIL, 2014) e pelas Diretrizes Curriculares Nacionais da Educação Básica (BRASIL, 2013).

Diante deste cenário, observa-se a prevalência da língua inglesa como componente curricular uma vez que a Base Nacional Comum Curricular (BRASIL, 2017) estabelece a sua obrigatoriedade nos currículos nacionais.

Isso ocorre em decorrência das políticas educacionais adotadas desde o pós Segunda Guerra Mundial (BRASIL, 1998) que preconizavam o ensino do idioma inglês como forma de aproximação dos interesses econômicos do país com o comércio exterior emergente. Para mais, o número de profissionais da área também corrobora com a escolha das escolas públicas, pois há maior quantidade de professores formados na língua inglesa do que em outras línguas estrangeiras. 
A prevalência da língua inglesa nas instituições públicas traz algumas dificuldades quanto ao seu ensino, acarretando desafios aos profissionais da área. Como parte desse panorama, podem-se destacar diferentes fatores presentes no cotidiano escolar como, por exemplo, as contradições das propostas curriculares de ensino, a falta de recursos destinados ao processo de ensino-aprendizagem, a diminuta carga horária na oferta da língua inglesa, a quantidade de alunos por sala, dentre diversas outras causas.

Sob esse cenário, diversos estudos são realizados com o propósito de encontrar meios alternativos que sejam capazes de auxiliar e/ou minimizar as dificuldades no processo de ensino-aprendizagem da língua inglesa. Esses estudos indicam que é preciso haver novas formas de mediação, seja por meio de mudança das metodologias de ensino ou pelo uso de diferentes recursos tecnológicos (BRUN; BRUN; MARQUES, 2017; MARZARI; BADKE, 2013; COOPER; SOUZA; TRAJANO, 2014; CHAGAS, 2013; SALESI, 2013; RAMOS; FURUTA, 2008).

Mesmo com a disposição e a preocupação dos docentes em proporcionar um aprendizado significativo e inovador, lidar com o processo de ensino-aprendizagem, em si, não é considerado uma tarefa simples.

Além disso, é preciso considerar que a aprendizagem de um idioma ocorre quando todos os envolvidos no processo assumem o protagonismo, ou seja, professores e alunos se mobilizam para que o ensino e a aprendizagem tenham uma dialogicidade. É fundamental organizar as responsabilidades de cada sujeito envolvido no processo sob a intencionalidade do objetivo de ensino, assim como as circunstâncias apropriadas à execução da atividade docente para os alunos.

Dessa maneira, encontram-se no conceito do Contrato Didático, desenvolvido por Guy Brousseau (2008), elementos que estabelecem relações no processo de ensino-aprendizagem e, possivelmente, considerados como recursos capazes de auxiliar na constituição de metodologias da língua inglesa para instituições públicas.

Por conseguinte, o presente estudo tem como objetivo apresentar uma discussão a respeito do Contrato Didático como instrumento pedagógico para o processo ensino-aprendizagem da língua inglesa na Educação Básica, de forma que as interações dos alunos sejam consideradas como um dos elementos orientadores na atividade docente.

Para tanto, foi realizada uma revisão bibliográfica (SILVEIRA; CÓRDOVA, 2009; PRODANOV; FREITAS, 2013), buscando articular os conceitos do Contrato Didático ao objeto de estudo elaborado pelos docentes no cotidiano escolar. Paralelamente, o presente estudo presume colaborar com concepções colaborativas à melhoria da oferta de ensino da língua inglesa nas instituições públicas, adentro as relações concebidas no decorrer de todo o processo. Ademais, pressupõe que a qualidade de ensino do idioma inglês seja capaz de formar cidadãos autônomos e preparados para o exercício social, pessoal e/ou profissional, além de contribuir com novas ideias e possibilidades de estudos no campo da língua inglesa na Educação Básica brasileira. 


\section{Os desafios presentes no processo de ensino-aprendizagem da língua inglesa no ensino público}

Diversos estudos sobre os grandes desafios enfrentados pelo ensino da língua inglesa na Educação Básica brasileira já foram, e ainda são, elaborados na última década (SALESI, 2013, CHAGAS, 2013, RAMOS; FURUTA, 2008; BRUN; BRUN; MARQUES, 2017; MARZARI; BADKE, 2012; COOPER; SOUZA; TRAJANO, 2014).

Mesmo com a diversidade de pesquisas com o propósito de contribuírem e evidenciarem distintas propostas, ideias e caminhos para o processo de ensino-aprendizagem dos alunos da língua inglesa no ensino regular público, a oferta do idioma inglês ainda abrange a presença de dificuldades em diversas instituições escolares. Por meio desses estudos, também é possível perceber as intermináveis buscas de diferentes ferramentas que possam ser contribuintes para o ensino da língua inglesa, como por exemplo o uso das tecnologias para o aprendizado de idiomas.

Alguns dos autores (SALESI, 2013, CHAGAS, 2013, RAMOS; FURUTA, 2008), levantam questionamentos sobre a inserção das ferramentas digitais que são consideradas benéficas na relação com o aprendizado de outro idioma aos alunos do ensino regular. As pesquisas realizadas por esses autores, são apresentadas e embasadas com a preocupação da modificação e, consequentemente, a renovação do ensino do idioma da língua inglesa sob os aspectos tecnológicos.

As ferramentas tecnológicas podem contribuir com a modificação do ensino, transformando-o em um objeto de estudo inovador e/ou atrativo, cooperando com o desenvolvimento e a melhoria da atividade docente diante do ensino e valorizando a construção do conhecimento dos alunos (RAMOS; FURUTA, 2008; CHAGAS, 2013).

Salesi (2013) considera a geração atual como pessoas nativas digitais. Entretanto, os recursos tecnológicos nem sempre são utilizados como um meio pedagógico capaz de colaborar com a atividade docente e o aprendizado dos alunos, seja pela dificuldade de acesso aos meios digitais ou por falta de habilidade dos alunos e professores em trabalhar com as tecnologias.

Assim, muitas vezes as propostas inovadoras que envolvem os recursos tecnológicos não alcançam as escolas públicas, inviabilizando o ensino da língua inglesa por esta via.

Os entraves para o processo de ensino-aprendizagem da língua inglesa não cessam por aí. Outros estudos (BRUN; BRUN; MARQUES, 2017; MARZARI; BADKE, 2012; COOPER, SOUZA; TRAJANO, 2014) apresentam uma série de dificuldades no processo de ensino-aprendizagem do idioma inglês, intervenientes em muitas realidades no contexto das escolas públicas. Nesse sentido, as questões variam, tais como: a carga horária insuficiente sobre a oferta de ensino, contradizendo algumas das propostas curriculares do Sistema Educacional brasileiro; a grande quantidade de alunos por sala; a falta de recursos, materiais ou de salas de língua estrangeira nas escolas públicas; a escassez da prática da 
língua; a heterogeneidade do conhecimento dos alunos; a falta de estratégias motivadoras, dentre outras.

Diante destas dificuldades apresentadas previamente, percebe-se que existem transformações no cenário da oferta de língua estrangeira as quais os professores enfrentam diariamente. Alguns dos impasses, como a carga horária insuficiente, as contradições das propostas educacionais etc., não são acessíveis diretamente pelos profissionais para possíveis modificações devido aos aspectos políticos. Enquanto os outros impasses, relacionados ao aprendizado e/ou à prática de ensino interiormente a sala de aula, podem permitir a autonomia dos profissionais à transformação da atividade docente, colaborando com o enfrentamento no cotidiano escolar e propiciando a aproximação do aprendizado da língua inglesa aos alunos.

Diante disto, independente das propostas de ensino elaboradas para os alunos, é necessário estabelecer as relações dos envolvidos com a intencionalidade do plano de aula.

Portanto, mesmo com as diversas dificuldades presentes no processo de ensino-aprendizagem da língua inglesa na Educação Básica pública, o presente estudo preocupou-se em discutir de que forma a interação dos alunos pode contribuir para as intencionalidades na atividade docente, independentemente de quais sejam.

Nesse sentido, esta pesquisa teve como foco elementos, conceituados cientificamente, que pudessem auxiliar nas relações proporcionadas no processo de ensino-aprendizagem dos alunos. Para tal, a investigação teve como ponto de partida, os pressupostos de outros estudos que foram considerados como aspectos proveitosos à investigação por apresentarem diversidades das interações e das intencionalidades nas realidades de ensino, sem delinear um ciclo específico no qual as estimativas devem ser aplicadas, mas viabilizem as relações de aprendizado em qualquer estágio da construção do conhecimento dos alunos.

\section{As contribuições do contrato didático nas relações do processo de ensino-aprendizagem}

Sob as inquietações evidenciadas, a revisão bibliográfica revelou estudos que apresentaram possíveis elementos contribuintes à elaboração de novos caminhos para as interações das relações na atividade docente. Um destes caminhos busca respaldo nas contribuições dos estudos de Guy Brousseau (2008), que por meio da Teoria das Situações Didáticas, cunhou o conceito de Contrato Didático.

A Teoria das Situações Didáticas está relacionada à uma esquematização situada por diversas fases. A principal característica é promover as condições para propiciar o protagonismo dos sujeitos envolvidos no processo de ensino-aprendizagem. O protagonismo está associado ao papel ativo dos alunos para conceber a ação e reflexão sobre a validação das justificativas selecionadas a cada situação, tarefa e/ou problema a ser solucionado, sem viabilizar apenas a atuação e o protagonismo dos professores, e sim desenvolver a criticidade dos alunos (BROUSSEAU, 2008; SILVA, 2010). 
Por sua vez, o Contrato Didático foi desenvolvido na França, na década de 1980, e surgiu no campo da Didática da Matemática (BROUSSEAU, 2008). Foi elaborado diante das investigações das regras estabelecidas nas Situações Didáticas, além das condições constituídas sob os objetos de estudo no processo de ensino aprendizagem dos alunos. As regras e as condições são definidas como implícitas e explícitas e estão presentes nas relações estabelecidas entre os professores, alunos e o objeto de estudo.

Para elucidar de que forma as regras implícitas e explícitas interferem no processo de ensinoaprendizagem dos conteúdos, destaca-se aqui que as regras não estão associadas somente aos acordos elaborados entre os alunos e professores no início do ano letivo, mas ocorrem durante as ações docentes e discentes. As ações variam das intencionalidades, explícitas, selecionadas pelos docentes como meios de alcançar o aprendizado às devolutivas dos discentes ante as intervenções que carregam significados implícitos sem a percepção dos alunos sobre o objeto de estudo (BROUSSEAU, 2008; SILVA, 2010; BELTRÃO; SOUZA; SILVA, 2010; ALMEIDA; LIMA, 2011; PIVATTO; SCHUMACHER, 2012; SOUZA; LIMA, 2014).

Estudos de Brousseau (2008), Silva (2010), Beltrão, Souza e Silva (2010), Almeida e Lima (2011), Pivatto e Schumacher (2012) e Souza e Lima (2014) mostram a busca das relações entre os envolvidos no processo de ensino-aprendizagem e elucidam que as regras do Contrato Didático não se encontram apenas nos acordos e/ou normas estabelecidas pelos docentes a serem cumpridos pelos alunos na sala de aula durante o período letivo. O Contrato Didático está constituído nas interações e/ou comportamentos concebidos no processo de ensino-aprendizagem e contemplados, tanto pelos professores quanto pelos alunos, perante as intencionalidades e os objetivos do saber ensinado, constituído em cada plano de aula no cotidiano escolar.

O saber ensinado está associado à transformação realizada pelos docentes, em conformidade com as estratégias pedagógicas/metodológicas elaboradas pelo professor, a fim de propiciarem o ensino de acordo com a realidade dos alunos/grupos no interior das orientações e propostas curriculares. Para mais, também intenciona-se fornecer as devidas responsabilidades de cada envolvido na sala de aula, em direção à construção do conhecimento.

Segundo Beltrão, Souza e Silva (2010), Silva (2010) e Brousseau (2008), as responsabilidades dos integrantes, sendo os professores e alunos, são realizadas não somente de acordo com a realidade escolar, mas também por regras explícitas e instituídas na relação da interação dos profissionais à orientação e efetivação do processo de ensino-aprendizagem, a fim de intensificar as interações providas da atividade docente.

Já nos estudos realizados por Almeida e Lima (2011), as relações delineadas como Contrato Didático entre os sujeitos no processo de ensino-aprendizagem, são apresentadas por meio de uma tríade composta por uma relação didática. 
O primeiro elemento da tríade é composto pela intencionalidade docente e o propósito é estabelecer as relações dos alunos com o objeto de estudo. O segundo elemento está presente nas devoluções dos alunos em conformidade com a condução do processo de ensino-aprendizagem, pois desta maneira, os profissionais têm a flexibilidade de organizarem e/ou ajustarem as intervenções de acordo com a necessidade do contexto escolar. Por fim, o terceiro elemento é composto pelo resultado das negociações advindas das interações entre os alunos e o professor, considerando as necessidades dos estudantes presentes no processo de aprendizagem.

Com relação ao ensino da língua inglesa, a aplicação do contrato didático depende da postura do professor em sua ação docente.

Inicialmente, o professor deve se familiarizar com os conhecimentos do idioma inglês que os alunos já possuem para que possa propor situações que representem desafios. Por exemplo, a partir das devoluções dos alunos no processo de ensino-aprendizagem, por um lado, é possível reconhecer o repertório da língua inglesa que estes possuem e, por outro, o que ainda precisa ser assimilado para o aprendizado significativo do idioma.

Diante destas informações, o professor inicia uma intervenção com os alunos para incentivá-los ao debate e discussão do objeto de estudo. A intervenção está relacionada às técnicas selecionadas e, posteriormente, aplicadas às assimilações da língua inglesa aos alunos, propiciando-lhes as devidas interações com o objeto de estudo.

Essa interação entre aluno, professor e objeto de estudo busca produzir novas intervenções integradas não somente às estruturas gramaticais, mas também envolvidas pelas habilidades orais, auditivas, escrita e compreensão da língua, estabelecendo a aproximação dos alunos com a língua estrangeira e promovendo um aprendizado real à expansão e autonomia do exercício social dos alunos.

Assim, a relação didática é constituída pelos sujeitos envolvidos na sala de aula, em conformidade com as intencionalidades dos conteúdos explorados, estimando as responsabilidades de cada sujeito no processo de ensino-aprendizagem e buscando viabilizar a melhoria da oferta de ensino.

As contribuições da prática do Contrato Didático são variadas e podem ser aplicadas em diferentes componentes curriculares no processo de ensino-aprendizagem. Especificamente na área da língua inglesa, as cooperações estão associadas do delineamento das ferramentas da prática docentes às interações dos alunos no cotidiano escolar.

A priori, por meio do Contrato Didático é possível obter uma prática docente embasada ante a designação das ferramentas pedagógicas/didáticas e metodológicas da língua inglesa, que aproximam as relações entre a teoria e a prática de ensino, oportunizando a oferta do idioma inglês, conforme as propostas de ensino, a intencionalidade docente a as necessidades do contexto escolar, elegendo caminhos fundamentados e alternativos que não sejam apenas reproduzidos. 
Com o delineamento inicial à efetivação da prática docente, o Contrato Didático também viabiliza a inserção do idioma inglês em conjunto das suas habilidades e competências, sem focar o ensino somente nas estruturas gramaticais. Além disso, corrobora com uma proposta contextualizada e, supostamente, atrativa no processo de ensino-aprendizagem de acordo com a vivência pessoal dos alunos.

As relações são importantes por contribuir com os papéis e as responsabilidades dos sujeitos durante o processo, valorizando o conhecimento prévio dos aprendizes, uma vez que a língua inglesa faz parte de diversas atividades no contexto dos alunos em direção ao desenvolvimento, à expansão e à autonomia do aprendizado do idioma estrangeiro.

\section{Considerações finais}

O ensino de língua estrangeira está inserido como um dos componentes das matrizes e propostas curriculares e a sua maior finalidade é fornecer a oportunidade de expansão e autonomia dos indivíduos para que possam escolher seus caminhos, na área pessoal, profissional ou cultural, usufruindo o exercício da nova língua de acordo com os seus desejos e objetivos.

A língua inglesa exerce uma forte influência em razão dos aspectos políticos e econômicos, ainda, sendo o idioma designado à inserção de diversas instituições de ensino brasileiras, incluindo as escolas públicas em várias regiões do território nacional.

No que diz respeito ao cenário escolar, lidar com o processo de ensino-aprendizagem do idioma inglês não demonstra ser uma realidade tão simples, pois expressa a confrontação de inúmeros dilemas e dificuldades em relação à oferta e a efetivação do processo aos alunos das escolas públicas brasileiras.

Muitos profissionais se preocupam em buscar e disponibilizar a qualidade de ensino para os alunos, desenvolvendo, constantemente, estudos para isso. Contudo, mesmo com essa dedicação contínua, pressupõe-se que as dificuldades estarão sempre presentes no processo de ensino-aprendizagem. Em contrapartida, é imprescindível lidar com os conflitos do cotidiano escolar a fim de propiciar a oferta de ensino do idioma aos alunos.

Nesse cenário de preocupações, o presente estudo investigou caminhos com o propósito de encontrar meios à colaboração da atividade docente aos profissionais, e como subsídio, encontraram-se os conceitos do Contrato Didático diante das relações constituídas no processo de ensino-aprendizagem. Isto porque, independente dos objetivos dos professores, de enfrentar e/ou superar os impasses do ensino e/ou buscar alternativas à inovação da prática docente, é requerido aos profissionais estabelecerem as relações de todos os envolvidos no processo com o ensino.

À vista dos conceitos apresentados pelo presente estudo, o conceito do Contrato Didático demonstra ser propício no processo de ensino-aprendizagem dos alunos. Isso porque o conceito auxilia os professores estabelecerem as relações fundamentais para a efetivação do processo de ensino- 
aprendizagem, além de ser considerado como um componente oportuno para o enfrentamento dos impasses no cotidiano escolar, visto que são numerosos e, inevitavelmente, paulatinos.

De fato, alguns dos impasses, como a quantidade de alunos por sala, a deficiência na carga horária e algumas contradições das propostas elaboradas pelo Sistema Educacional, não são abrangidos diretamente pelos professores, e as demais dificuldades presentes são fatores que prejudicam o desenvolvimento dos alunos e o percurso do ensino.

Sob essa perspectiva, a maior finalidade do presente estudo foi apresentar as contribuições da articulação do conceito do Contrato Didático para o processo de ensino-aprendizagem da língua inglesa, como um caminho possível à atividade docente do ensino regular público.

A tríade do Contrato Didático propiciada por meio das relações entre os alunos, os professores e o ensino da língua inglesa no processo de ensino-aprendizagem é o caminho alternativo contribuinte para a melhoria da oferta de ensino.

Para melhor explanação, as possibilidades da inserção do Contrato Didático no processo de ensinoaprendizagem da língua inglesa no ensino regular podem encontrar-se nos delineamentos pedagógicos dos professores ao selecionarem as próprias ferramentas para a efetivação de seus planejamentos diários no interior da sala de aula. Paralelamente, o conjunto dos elementos pedagógicos/didáticos e metodológicos que são selecionados pelas abordagens e/ou métodos de língua estrangeira à efetivação da prática docente em conformidade das necessidades dos alunos, também integram as possibilidades da realização do Contrato e intensificam as relações entre as intervenções dos professores sobre a intencionalidade do objeto de estudo concedido para os aprendizes.

Ainda, durante este encadeamento, o surgimento das intervenções docentes, em cada momento do processo de ensino-aprendizagem, pode ser considerado como outra característica presente no conceito do Contrato Didático, colaborando para o percurso do aprendizado dos alunos e promovendo, além das responsabilidades, o papel ativo de cada sujeito.

Para os alunos, o Contrato Didático concede a valorização do papel discente no processo de ensinoaprendizagem de língua estrangeira tornando-os sujeitos ativos e colaboradores por meio de suas responsabilidades sob as mediações dos professores.

Isso permite que ocorra uma aprendizagem significativa do idioma inglês de maneira relacional, por meio da articulação entre a compreensão e o exercício natural do idioma.

Consequentemente, o objeto de estudo, integrado aos conteúdos, às habilidades e às competências da língua inglesa em cada etapa do ensino, é fornecido diariamente para os alunos independentemente das dificuldades do cotidiano escolar, em prol da superação dos obstáculos e a melhoria da oferta de ensino em qualquer nível da Educação Básica das escolas públicas. 
Finalmente, a oportunidade de ensino de língua estrangeira como direito dos indivíduos, assegurado pelas legislações, é garantida para todos os alunos de acordo com as demandas do sistema educacional brasileiro.

\section{Referências}

ALMEIDA, Fernando Leite; BRITO LIMA, Anna Paula Avelar. Os Efeitos de Contrato Didático Na Sala de Aula de Matemática (CO). In: XIII Conferência Interamericana de Educação Matemática. 2011.

BELTRÃO, Rinaldo Cesar; SOUZA, Carla Maria Pinto; SILVA, Cláudia Patricia Silverio. Contrato Didático e suas influências na sala de aula. Educação Matemática Pesquisa, 2010, 12.2.

BRASIL. Lei de Diretrizes e Bases. Lei nº 9.394/96, de 20 de dezembro de 1996.

. Ministério da Educação. Base Nacional Comum Curricular, Educação é a Base, 2017.

Ministério da Educação e do Desporto, Secretaria de Educação Fundamental. Parâmetros Curriculares Nacionais, terceiros e quartos ciclos do ensino fundamental - Língua Estrangeira. Brasília, 1998.

. Ministério da Educação. Secretaria de Educação Básica. Secretaria de Educação Continuada, Alfabetização, Diversidade e Inclusão. Secretaria de Educação Profissional e Tecnológica. Conselho Nacional da Educação. Câmara Nacional de Educação Básica. Diretrizes Curriculares Nacionais Gerais da Educação Básica / Ministério da Educação. Secretaria de Educação Básica. Diretoria de Currículos e Educação Integral. Brasília: MEC, SEB, DICEI, 2013.

. Plano Nacional de Educação - PNE/Ministério da Educação. Brasília, DF: INEP, 2014.

BROUSSEAU, G. Introdução a teorias das Situações Didáticas: conteúdos e métodos de ensino. São Paulo: Ática, 2008.

BRUN, Erik; BRUN, Milenna; MARQUES, Paloma. A aprendizagem de língua estrangeira na escola regular: desafios e possibilidades. A Cor das Letras, 2017, 5.1: 12-26.

CHAGAS, Lucas Araujo. O uso de ferramentas da internet no ensino de língua inglesa e seus reflexos na inclusão social de alunos de escolas públicas. Texto Livre: Linguagem e Tecnologia, 2013, 6.1: 63-75.

COOPER, Jennifer Sarah; TRAJANO, João Evangelista; SOUZA, Lidiane Cristina. Desafios do ensino da língua inglesa como língua estrangeira (ILE) em escolas públicas de Santa Cruz, RN. Working Papers em Linguística, 2014, 15.1: 43-56.

MARZARI, Gabriela Quatrin; BADKE, Mariluza Ribeiro. Ensino e aprendizagem de língua inglesa em escolas públicas de Santa Maria/RS. Coleção Digital PUC Rio, 2013.

PIVATTO, Wanderley; SCHUHMACHER, Elcio. A tríade relação professor-estudante-saber nas aulas de Matemática: implicações do contrato didático na análise das expectativas dos sujeitos. Estação Científica (UNIFAP), 2014, 2.2: 95-103.

PRODANOV, Cleber Cristiano; FREITAS, Ernani Cesar de. Metodologia do Trabalho Científico: Métodos e Técnicas da Pesquisa e do Trabalho Acadêmico, $2^{\mathrm{a}}$ Ed., Novo Hamburgo - RS, Associação Pró-Ensino Superior em Novo Hamburgo - ASPEUR Universidade Feevale, 2013.

RAMOS, Samantha Gonçalves Mancini; FURUTA, Susy Maria Zewe Coimbra. Novas tecnologias nas aulas de língua inglesa: aprimorando o processo de ensino/aprendizagem. Acta Scientiarum. Language and Culture, 2008, 30.2: 197-203.

SALESI, Camila Carla. O uso pedagógico da internet nas aulas de Língua Inglesa. In Norte, Mariangela Braga. Desafios para a docência em Língua inglesa [recurso eletrônico]: teoria e prática. São Paulo: Universidade Estadual Paulista: Núcleo de Educação a Distância, 2013.

SÃO PAULO (Estado) Secretaria da Educação. Proposta curricular do Estado de São Paulo para o ensino de língua estrangeira moderna para o ensino fundamental Ciclo II e ensino médio. São Paulo: SE, 2008. SILVA, Benedito Antonio da Silva. Contrato didático. In: MACHADO, Silvia Dias A. Educação Matemática: uma introdução. $2^{\mathrm{a}}$ ed. São Paulo: EDUC, 2010, 49-75. 
SILVEIRA, Denise Tolfo; CÓRDOVA, Fernanda Peixoto. Unidade 2-A pesquisa científica. Métodos de pesquisa, 2009, 31-42.

SOUZA, Carla Maria Pinto; LIMA, Anna Paula de Avellar Brito. O Contrato Didático a partir da aplicação de uma sequência didática para o Ensino de Progressão Aritmética. Zetetike, 2014, 22.2: 31-61.

Camila Vieira Cassiano, Master in Education by the Universidade Municipal de São Caetano do Sul (2018), Specialist in English Language by the Universidade Metodista de São Paulo (2013). Graduated in Language by the Universidade Bandeirante de São Paulo since 2011. English language teacher in elementary and high school.E-mail: camila.vcassiano@gmail.com.

Ivo Ribeiro de Sá, Graduated in Physical Education by the Faculdade de Educação Física de Santo André (1985), Master (2001) and Doctorate (2015) in Education by PUC-SP. Professor at the Professional Master's Program in Education. Researcher linked to the group Training of education professionals and educational practises.E-mail: ivo.sa@prof.uscs.edu.br. 